\title{
Gestão da Diversidade nas Organizações como Prática Gerencial
}

\author{
Andrei Moreira Neves ${ }^{1}$
}

\begin{abstract}
Resumo
O presente trabalho visa esclarecer o papel da gestão de pessoas em relação as políticas de diversidade nas organizações. O problema da pesquisa é identificar como as organizações têm lidado com a gestão da diversidade de pessoas. O objetivo geral é elucidar a gestão da diversidade nas organizações e o papel da gestão de pessoas como fator de sucesso na inserção dessa prática gerencial. A pesquisa será bibliográfica através de um levantamento bibliográfico realizado em periódicos de língua portuguesa que tenham sido publicados a partir do ano 2000, visando um olhar mais moderno sobre o assunto, posteriormente submetidos a uma análise de conteúdo do tipo temática. Os autores que deram base a pesquisa foram: Alves e Galeão-Silva (2004); Fleury (2000); Irigaray e Vergara (2011); e Saraiva e Irigaray (2009). Como resultado, observou-se que a gestão da diversidade vem sendo debatida dentro das empresas situadas no Brasil, através de políticas que tratam o tema. Porém os avanços foram pequenos e a prática é diferente da política. $\mathrm{O}$ tema vem sendo associado nas organizações mais como fator de diferenciação mercadológica do que uma prática voltada à estratégia na gestão de pessoas.
\end{abstract}

Palavras-chave: Gestão; Recursos Humanos; Minorias.

\section{Diversity Management in Organizations as a Management Practice}

\begin{abstract}
This paper aims to clarify the role of people management in relation to diversity policies in organizations. The research problem is to identify how organizations have dealt with managing the diversity of people. The general objective is to clarify the management of diversity in organizations and the role of people management as a success factor in the insertion of this management practice. The research will be bibliographic through a bibliographic survey carried out in Portuguese-language journals that have been published since the year 2000, aiming at a more modern look on the subject, later submitted to a thematic content analysis. The authors who supported the research were: Alves and GaleãoSilva (2004); Fleury (2000); Irigaray and Vergara (2011); and Saraiva and Irigaray (2009). As a result, it was observed that diversity management has been debated within companies located in Brazil, through policies that address the issue. However, progress has been small
\end{abstract}

\footnotetext{
${ }^{1}$ Especialização em Gestão Estratégica de Pessoas pela Faculdade Educacional da Lapa - FAEL e Graduação em Administração pela Universidade Federal da Fronteira Sul - UFFS. Professor no Serviço Nacional de Aprendizagem Industrial. E-mail: andreimoreiraneves@gmail.com
} 
and the practice is different from politics. The theme has been associated in organizations more as a factor of market differentiation than a practice focused on strategy in people management

Keywords: Management; Human Resources; Minorities. 


\section{O Papel da Gestão de Pessoas para uma Eficaz Gestão da Diversidade nas Organizações}

\section{Introdução}

Em um ambiente cada vez mais competitivo e mutante, as organizações necessitam se adaptar a novas realidades e exigências de mercado. A gestão da diversidade se torna um aspecto vital para a sobrevivência de muitas empresas, tendo em vista a expertise que isso proporciona para o contexto organizacional e consequentemente a evolução das atividades empresariais.

Quando se aborda o tema diversidade, o Brasil se destaca por ser diverso em cultura, religião, etnias etc. $\mathrm{O}$ tema chama a atenção por tratar da inserção e manutenção de pessoas diversas no mercado de trabalho, refletindo de forma positiva na sociedade ao se obter resultados significativos através desta prática gerencial. Frente a isso, buscou-se responder ao seguinte questionamento: Como ocorre a gestão da diversidade em empresas situadas no Brasil?

Com o intuito de responder tal questionamento, tem-se como objetivo geral deste trabalho: elucidar a gestão da diversidade nas organizações e o papel da gestão de pessoas como fator de sucesso na inserção desta prática gerencial; como objetivos específicos, apresentam-se: a) Abordar sobre a diversidade e as minorias; b) Discorrer sobre a política de diversidade nas organizações; c) Expor o resultado de pesquisas realizadas no Brasil; d) Apresentar o papel da gestão de pessoas na gestão da diversidade.

Esta pesquisa possibilita para a academia bases para compreender a dimensão e os impactos da diversidade no ambiente organizacional e uma modernização das práticas de gestão de pessoas para acompanhar as mudanças em busca de melhores resultados organizacionais. Estudos com base na diversidade possibilitam um debate sobre melhores condições de trabalho e a oportunidade para pessoas que são ignoradas e desmerecidas pelo mundo corporativo, ficando na maioria das vezes alocadas em cargos operacionais.

O foco central do estudo foi demonstrar a importância da diversidade nas organizações e a necessidade de uma gestão de pessoas com um olhar atento para que ocorra um estímulo nos departamentos de recursos humanos. Para atingir o objetivo proposto, empregou-se como método a pesquisa bibliográfica.

\section{Método e discussão}


Neste tópico será exposta a revisão da literatura, seguida dos procedimentos metodológicos e da análise e discussão dos resultados.

\subsection{Revisão da literatura}

Abaixo será apresentada a fundamentação teórica, destacando as principais ideias que cercam o presente trabalho. No primeiro tópico será exposta a questão da diversidade e das minorias; em um segundo momento o que são políticas de diversidade nas organizações; posteriormente a será apresentada a relação entre a gestão de pessoas e a diversidade; e por fim, serão expostos os resultados de algumas pesquisas realizadas no Brasil.

\subsubsection{Diversidade e minorias}

Na década de 1980, começaram a surgir estudos relacionados a diversidade nas organizações, que questionavam como as diferenças individuais influenciavam as empresas (IRIGARAY; VERGARA, 2011), conforme destaca Fleury (2000), o tema começa a ser abordado nas empresas subsidiárias americanas. Estas influências se relacionam com o comportamento organizacional, que investiga o impacto que os indivíduos têm nas organizações (ROBBINS, 2005), quando se aborda a mudança organizacional, há diretamente associada a ela a resistência das pessoas (CARVALHO; NASCIMENTO; SERAFIM; 2012).

Para autores como Alves e Galeão-Silva (2004), a gestão da diversidade é mais efetiva para o enfrentamento das desigualdades sociais, pois possuem como cerne a meritocracia. Segundo eles, a gestão da diversidade é defendida com base em dois pontos: programas internos com uma visão de justiça e; gerenciamento da diversidade de pessoas para a criação de vantagem competitiva, elevando o desempenho da empresa. Para Fleury (2000) a gestão da diversidade se desenvolve com foco na criação de vantagem competitiva, corroborando com Alves e Galeão-Silva (2004).

A gestão da diversidade, no Brasil, encontra força na discriminação de diversos grupos que historicamente foram marginalizados e privados de sua cidadania. Ao se abordar o tema diversidade, é possível identificar a expressão "minorias". Este termo, através da sociologia, desconsidera o número de membros e concentra-se na disposição de poder na sociedade, ou seja, é utilizado para descrever os grupos menos favorecidos na sociedade (ALVES; GALEÃO-SILVA, 2004). Com isso, há variados aspectos que podem ser considerados em relação a diversidade como: sexo, idade, grau de instrução, origem, raça e 
língua, ou seja, a diversidade é um mix de pessoas diferentes, convivendo em um mesmo sistema social (FLEURY, 2000).

\subsubsection{Política de diversidade nas organizações}

Um fator relevante no momento de decisão para a implementação ou não de uma política de diversidade está pautado nas mudanças que vão além de procedimentos administrativos, pois é preciso uma mudança cultural (ALVES; GALEÃO-SILVA, 2004). A mudança cultural demanda tempo e recursos, assim a organização necessita estar segura e confiante do caminho que irá seguir.

É notável que no momento de recrutar novos funcionários, as empresas são dirigidas conforme a lógica do mercado, que buscam profissionais disponíveis no mercado e qualificados, sendo que historicamente, as minorias são mais caras de se recrutar e menos qualificadas. Existe uma predeterminação nas práticas de recrutamento e seleção que dificultam a inserção das minorias no ambiente de trabalho (ALVES; GALEÃO-SILVA, 2004).

Em determinado momento a contratação de pessoas vindas de minorias se tornou inevitável e os gestores inseriram a gestão da diversidade como uma prática gerencial, tornando uma variável incontrolável em controlável e funcional, adotando ainda um discurso com vistas ao reconhecimento do mercado para tal atitude, mercantilizando a diversidade ao invés de tratá-la como prática para a mudança social (ALVES; GALEÃO-SILVA, 2004). A gestão da diversidade foi uma resposta empresarial ligada a competividade (FLEURY, 2000).

Com a presença da diversidade no contexto organizacional, provocam-se impactos relacionados a eficácia tanto organizacional como individual, para tal é preciso de um espaço propicio para isso (FLEURY, 2000). Fleury (2000) destaca que o objetivo principal da gestão da diversidade nas organizações é administrar as relações de trabalho e as práticas organizacionais para compor a sua força de trabalho interna, com vista a atração e retenção dos talentos que se encontram nos chamados grupos de minoria.

Estamos inseridos em uma sociedade estratificada $\mathrm{e}$ as pessoas possuem oportunidades diferentes, sendo que a obtenção de prestígio é limitada por fatores como a origem econômica e também racial (FLEURY, 2000). As empresas são consideradas instrumentos de modificação da sociedade (ALVES; GALEÃO-SILVA, 2004), desse modo, não seria pertinente em se tratando de força de trabalho diversa haver um olhar mais humano e em prol da equidade? 


\subsubsection{O resultado de pesquisas realizadas no brasil}

Os autores Alves e Galeão-Silva (2004) realizaram uma pesquisa através de um levantamento bibliográfico no período entre 1997 e 2002 referente a gestão da diversidade e utilizaram a técnica de análise de conteúdo em seu estudo. Os autores encontraram duas categorias que se relacionam com diversidade. A primeira são as ações afirmativas, em que se visualiza os fenômenos sociais como não-naturais e resultantes das interações sociais, necessitando de uma intervenção política - governo-; a segunda baseia-se na ideia de gestão da diversidade, em que há a adoção de medidas administrativas para que seja alavancado o desempenho organizacional.

Ao incluir as minorias nas organizações, há um olhar mercadológico, em que as diferenças se transformam em vantagem competitiva e posteriormente ocorre uma transformação e passam a ser um recurso que pode ser gerenciado. "Por fim, as diferenças são neutralizadas ao serem transportadas para o campo em que todas as coisas são mercadorias" (ALVES; GALEÃO-SILVA, 2004, pág. 28).

Saraiva e Irigaray (2009) pesquisaram se as políticas de diversidade nas organizações são apenas um item de discurso. No artigo analisaram a efetividade da implementação de políticas voltadas à diversidade em filiais brasileiras de uma empresa multinacional.

Para os autores, a questão da diversidade se tornou relevante nas organizações a partir da identificação de diferenças na força de trabalho. Eles destacam que o assunto não é novo, mas que é necessário pautar-se devido a um discurso moderno, porém com práticas conservadoras.

A efetividade da prática pró-diversidade é justificada a partir de uma igualdade de oportunidades para todos os colaboradores da empresa. Os gestores lidam com os empregados, como se a hierarquia se sobressairia em relação as diferenças (SARAIVA; IRIGARAY, 2009), ou seja, que todos teriam uma condição "padrão".

$\mathrm{Na}$ investigação, observou-se que a legislação é cumprida e mascarada por um discurso de responsabilidade social empresarial, voltando-se para a lógica do mercado e não para sua importância social. Os autores complementam que as práticas voltadas à diversidade são uma discriminação disfarçada em que não há um tratamento igualitário.

Nos relatos dos participantes da pesquisa identificou-se que as discriminações ocorridas no ambiente de trabalho não são tratadas e que há um receio em se manifestar sobre isso. Em cargos de liderança não há a presença das minorias, o que desqualifica uma política de diversidade, visto que as oportunidades não são igualitárias. Os pesquisadores 
identificaram relatos que demonstram que há uma remuneração inferior às minorias em relação aos seus pares.

Nas falas das não-minorias observou-se a utilização de termos pejorativos e não condizentes com a realidade de uma empresa que preza pela diversidade. Há ali uma desvalorização da mulher, intolerância em relação aos homossexuais e tratamento desigual com os negros. Os pesquisadores identificaram o humor como um meio não penas de comunicação, mas de discriminação.

Por fim, a formalização de uma política de diversidade é condição necessária, mas insuficiente para a sua efetividade. A política de diversidade ainda está direcionada à uma projeção de imagem para atingir o mercado e os consumidores. A empresa embora regida por políticas formais, não as vivencia e é notável uma impunidade de comportamentos discriminatórios, bem como um preconceito dos empregados e da própria gerência (SARAIVA; IRIGARAY, 2009).

Irigaray e Vergara (2011) realizaram um estudo sobre as transformações ocorridas com o tempo sobre a política de diversidade em uma empresa aérea brasileiras que absorveu deficientes físicos. Ocorreu uma primeira investigação cinco anos antes, e posteriormente se retornou para avaliar os impactos após este tempo.

Em um primeiro momento foi analisada a percepção dos usuários da empresa e constatou-se que no discurso utilizaram figuras de linguagem que propiciam uma ideia de politicamente correto, o que os investigadores enquadraram como um discurso que mascara eventuais conflitos políticos ou sociais.

Nas falas realizadas pelos colegas, há a presença de um discurso voltado à imagem da empresa, na forma como contratar deficientes físicos possibilita uma certa admiração do público, ou seja, uma visão voltada ao mercado.

Com as entrevistas para os empregados deficientes, os autores identificaram um senso de identidade social coletiva em que a atitude da empresa associa-se a restauração de um direito que lhes foi negado, mas que há condições de trabalho inadequadas, visto as suas limitações físicas e que durante as interações sociais, as pessoas não sabiam lidar com o "diferente", sugerindo certa ignorância ou preconceito. O discurso destes empregados é frustrado, relatando a falta de oportunidades para ascensão profissional.

Os autores classificaram a empresa como um espaço em que os indivíduos convivem de maneira funcional e neutra com foco nos objetivos econômicos organizacionais, representando uma administração ineficiente. Por fim destacam que é necessário reformular as práticas e políticas organizacionais. 


\subsubsection{A gestão de pessoas e a diversidade}

É possível observar que as empresas aderiram a um processo de adaptação em relação a diversidade, visto o foco na necessidade de mão-de-obra diversa e com isso, a busca por competitividade. Esse fato caracteriza a busca por desenvolvimento organizacional, que é a revisão da estrutura da empresa, e que envolve as pessoas, buscando um ajuste mais adequada em relação ao mercado (CARVALHO, 2012).

Existem três princípios para o desenvolvimento organizacional, elencados como um processo sistemático de técnicas para os grupos organizacionais.

Figura 1: Princípios básicos para o desenvolvimento organizacional

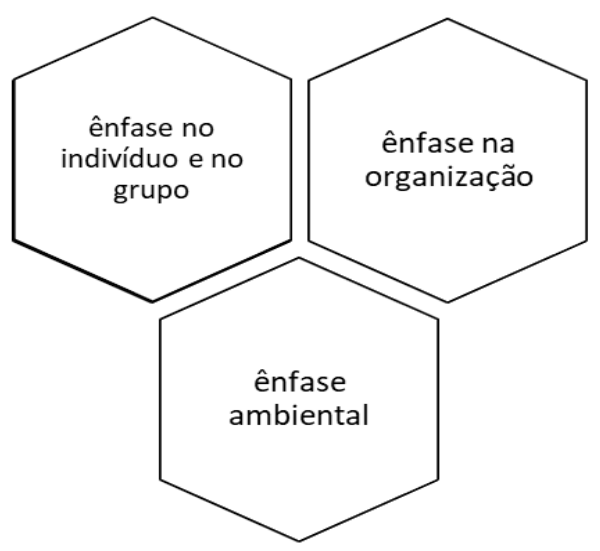

Fonte: Adaptado de Carvalho et al., 2012.

Tendo em vista a ideia de princípios apresentada por Carvalho et al. (2012), é possível perceber tais práticas na gestão da diversidade. A ideia do autor é que as ênfases possuem uma aplicação prática nos grupos como forma de técnica de dinâmica grupal. É importante salientar que esse é um processo sistemático, ou seja, um depende do outro para se atingir um resultado positivo. Em relação a gestão da diversidade, é pertinente trabalhar os indivíduos e o grupo, as lideranças e a cultura organizacional.

Na ênfase no indivíduo e no grupo é possível perceber a importância da atuação do líder do grupo e o modo como as experiências impactam nos indivíduos. Na pesquisa de Saraiva e Irigaray (2009), foi possível identificar que a ação de um diretor coloca em xeque toda a política de diversidade que é empregada na organização, demonstrando a relevância e significado que há na interação do líder. 
Em relação a organização, essa ênfase percorre as atividades de socialização grupal, educação e administração. Propõe o enfrentamento das diferenças e a eliminação de problemas que geram queixas e angústias. Na pesquisa de Saraiva e Irigaray (2009), se notou a forte presença do silencio frente as discriminações, devido à falta de um apoio da empresa, que seriam as atividades de socialização e educação. Observa-se também no estudo de Irigaray e Vergara (2011), a fala frustrada dos empregados deficientes em relação a ascensão profissional, apresentando uma falha nas atividades de administração.

$\mathrm{Na}$ ênfase ambiental, percebe-se um afastamento significativo entre a teoria (políticas de diversidade documentadas) e as práticas organizacionais. As empresas possuem uma visão primordialmente focada no mercado, o que gera um impasse entre a real necessidade das políticas organizacionais voltadas às minorias, que está na busca por oportunidades igualitárias.

\subsection{Procedimentos metodológicos}

O presente trabalho irá apresentar o fenômeno da diversidade nas organizações e com isso. Caracteriza-se como uma pesquisa básica, por propiciar conhecimento a respeito do tema (PRODANOV, 2013), em relação aos seus objetivos é descritivo-exploratório, pela finalidade de descrever e estabelecer relação entre as variáveis analisadas, que são a gestão de pessoas e a diversidade. Existe uma preocupação em demonstrar a atuação prática nas organizações (GIL, 2008). Para isso utilizará o procedimento técnico da pesquisa bibliográfica, que é desenvolvida com base em material já elaborado, constituído principalmente de livros e artigos científicos (GIL, 2008).

Conforme observa, é importante em pesquisas bibliográficas verificar o lapso temporal e a veracidade das informações. Foram selecionados apenas artigos publicados a partir de 2000 e o levantamento bibliográfico foi realizado nas seguintes fontes: Cadernos EBAPE.BR e Revista de Administração de Empresas. Selecionou-se estas fontes por abordarem periódicos com foco na área da Administração e conforme a classificação Qualis da Coordenação de Aperfeiçoamento de Pessoal de Nível Superior (Capes) são A2, uma das melhores avaliações. "O Qualis-Periódicos é um sistema usado para classificar a produção científica dos programas de pós-graduação no que se refere aos artigos publicados em periódicos científicos" (PLATAFORMA SUCUPIRA, 2019), deste modo, os artigos destas fontes e que foram utilizados são considerados de excelente qualidade científica. 
Para a seleção dos artigos, pesquisou-se os termos: diversidade e gestão da diversidade. Os artigos encontrados foram submetidos a uma análise de conteúdo do tipo temática, em que se trabalha com a noção de tema, buscando afirmações a respeito do assunto pesquisado (GERHARDT; SILVEIRA, 2009), para a seleção dos artigos foi realizada a leitura dos resumos para verificar a adesão a temática pesquisada e por fim, foram selecionados quatro artigos para a base desta pesquisa. Ocorreu a seleção de três artigos da Revista de Administração de Empresas (RAE) e um artigo do Cadernos EBAPE.BR.

\section{Análise e discussão de resultados}

Os artigos selecionados abordaram a temática compreendida nessa pesquisa e propiciaram informações relevantes à sua análise. Alguns artigos visualizados no momento da pesquisa não são oriundos de uma pesquisa base e inédita no que tange a diversidade, deste modo não foram incluídos nessa análise. Optou-se por artigos que possuem no seu escopo uma pesquisa realizada pelos autores sobre o tema.

Quadro 1: Resumo dos artigos científicos selecionados.

\begin{tabular}{|c|c|c|c|c|}
\hline FONTE & TÍTULO & $\begin{array}{l}\text { PALAVRAS- } \\
\text { CHAVE } \\
\end{array}$ & AUTOR (ES) & $\begin{array}{c}\text { ANO DE } \\
\text { PUBLICAÇÃO }\end{array}$ \\
\hline RAE & $\begin{array}{l}\text { Gerenciando a diversidade } \\
\text { cultural: experiências de } \\
\text { empresas brasileiras. }\end{array}$ & $\begin{array}{c}\text { Diversidade } \\
\text { cultural; } \\
\text { Administração de } \\
\text { recursos humanos; } \\
\text { Estudos } \\
\text { comparativos. }\end{array}$ & $\begin{array}{l}\text { Maria Tereza } \\
\text { Leme Fleury }\end{array}$ & 2000 \\
\hline RAE & $\begin{array}{c}\text { A crítica da gestão da } \\
\text { diversidade nas organizações }\end{array}$ & $\begin{array}{l}\text { Diversidade; } \\
\text { Ação afirmativa; } \\
\text { Gestão da } \\
\text { diversidade; } \\
\text { Teoria crítica; } \\
\text { Racismo. } \\
\end{array}$ & $\begin{array}{c}\text { Mario Aquino } \\
\text { Alves; } \\
\text { Luis } \\
\text { Guilherme } \\
\text { Galeão-Silva. }\end{array}$ & 2004 \\
\hline RAE & $\begin{array}{c}\text { Políticas de diversidade nas } \\
\text { organizações: uma questão de } \\
\text { discurso? }\end{array}$ & $\begin{array}{c}\text { Diversidade } \\
\text { organizacional; } \\
\text { Discursos } \\
\text { empresariais; } \\
\text { Políticas de } \\
\text { inclusão; } \\
\text { Políticas de } \\
\text { diversidade; } \\
\text { Análise do discurso. }\end{array}$ & $\begin{array}{l}\text { Luiz Alex } \\
\text { Silva Saraiva; } \\
\text { Hélio Arthur } \\
\text { Reis Irigaray; }\end{array}$ & 2009 \\
\hline $\begin{array}{l}\text { Cadernos } \\
\text { EBAPE.BR }\end{array}$ & $\begin{array}{l}\text { O tempo como dimensão de } \\
\text { pesquisa sobre uma política de } \\
\text { diversidade e relações de } \\
\text { trabalho. }\end{array}$ & $\begin{array}{c}\text { Tempo; } \\
\text { Deficiente; } \\
\text { Inclusão; } \\
\text { Inocência útil; } \\
\text { Inocência inútil. }\end{array}$ & $\begin{array}{c}\text { Hélio Arthur } \\
\text { Reis Irigaray; } \\
\text { Sylvia } \\
\text { Constant } \\
\text { Vergara. }\end{array}$ & 2011 \\
\hline
\end{tabular}


Fonte: O autor, 2019.

A seleção dos artigos citados ocorreu por possuírem foco na gestão da diversidade em empresas situadas no Brasil e focando essencialmente em gestão empresarial. Com vistas a uma modernização da gestão de pessoas optou-se por artigos publicados mais recentemente, mas por ser um tema relativamente novo nas organizações tem-se publicações que variam de 2000 a 2011

A gestão da diversidade é vista no Brasil, como uma maneira de alavancar os resultados das empresas com cunho mercadológico, adaptado à lógica produtiva (ALVES; GALEÃO-SILVA, 2004). As políticas tendem a ser diferentes da prática, o que impacta diretamente nos grupos que são denominados de minorias.

Percebe-se que houve uma evolução no decorrer dos últimos anos em relação ao tema diversidade, com uma preocupação na integração de diversas pessoas no mundo corporativo, porém há a exigência de um olhar mais maduro dos gestores e líderes destas organizações. Mesmo com os avanços ocorridos, existe o grande desafio de possibilitar condições de trabalho e carreira para todos os profissionais. Como destacaram Saraiva e Irigaray (2009), existe uma divergência entre modernidade de discurso e o conservadorismo das práticas.

O Brasil é um país diverso e as empresas necessitam compreender que essa característica tende a beneficiar os seus resultados, em contrapartida é necessário possibilitar o sucesso profissional e condições para que as pessoas tenham um desenvolvimento constante. As empresas são instrumentos de modificação da sociedade (ALVES; GALEÃOSILVA, 2004), as políticas e práticas precisam estar alinhadas e acontecerem, para que as minorias possam ter ascensão profissional.

Devido ao preconceito dos empregados, a passividade gerencial e a ausência de um senso coletivo de diversidade (SARAIVA; IRIGARAY, 2009), percebe-se que a questão de integração das minorias está longe do ideal em nosso país. Irigaray e Vergara (2011) classificaram como um modo funcionalista de se administrar, em que a diversidade é negligenciada e as empresas não sabem administrar as múltiplas identidades presentes nas organizações, contribuindo para a exclusão dessas pessoas.

No que tange ao papel da gestão de pessoas, quando se refere ao tema diversidade, identifica-se que há uma mudança necessária. Através de um novo olhar que possibilite às organizações uma atualização de suas práticas e a percepção de suas responsabilidades frente a sociedade. Soto (2010) aborda a mudança em seu livro e afirma que "coisas que não são 
deixadas podem transformar-se em uma bagagem demasiadamente pesada para carregar, um obstáculo para o trânsito da liberdade".

Quando se aborda mudança na gestão da diversidade é possível utilizar o que Soto (2010) destaca e perceber que a essa carga pesada vai refletir nos resultados organizacionais e enfraquecer o desenvolvimento da empresa como um todo. Cada vez mais os consumidores estão mais informados e as empresas que não evoluem tendem a ser deixadas de lado no momento da escolha entre as diversas possibilidades de compra (KOHN, 2019).

A contribuição de uma gestão estratégica de pessoas no campo da diversidade é perceptível com a identificação de políticas bem estruturadas nas organizações, mas que falham em relação a prática (FLEURY, 2000). A gestão de pessoas, se empregada de forma estratégica nas empresas podem cooperar com os diversos departamentos e oferecer profissionais mais motivados e preparados para os desafios organizacionais.

\section{Considerações finais}

Uma sociedade moderna exige organizações atualizadas em relação a políticas, mas principalmente em relação as suas práticas. Ao fim da presente pesquisa observou-se que o Brasil possui um desafio gigante no que tange à atualização em relação as práticas empresariais voltadas para a gestão da diversidade.

Com o advento do debate sobre diversidade nas empresas subsidiárias americanas situadas no Brasil na década de 1980, percebe-se que com o transcorrer de diversos anos há pouca evolução. As práticas empresariais devem responder às políticas de diversidade, o que não vem sendo a realidade brasileira.

A hipótese apresentada torna-se verdadeira, pois o tema não vem sendo tratado como uma forma estratégica de se gerenciar as pessoas na organização, mas focando em mercado, direcionando os esforços para uma vantagem competitiva que não se sustenta conforme destacou a investigação de Irigaray e Vergara (2011).

O objetivo geral foi alcançado, visto que esclareceu a gestão da diversidade nas organizações e que o tema deve ser tratado como uma responsabilidade do departamento de gestão de pessoas. Atendeu-se os objetivos específicos esclarecendo o que é diversidade e minorias; política de diversidade nas organizações; pesquisas realizadas no Brasil; e o papel da gestão de pessoas. Desse modo, vislumbrando uma atuação estratégica voltada para o desenvolvimento humano, desprendendo a noção de diversidade como diferenciação de mercado. 
Conforme percebe-se, o problema de pesquisa foi esclarecido, pois a gestão de diversidade no Brasil não é tratada como uma prática gerencial de responsabilidade do departamento de gestão de pessoas. O que acontece é que as políticas organizacionais trazem como se fosse assim, mas na prática existe um foco mercadológico. Nesse sentido, é necessário alinhar políticas e práticas.

Por fim, sugere-se novas pesquisas com foco na gestão da diversidade nas organizações para que o tema possa ser melhor esclarecido na academia e que estimule melhores práticas nas empresas brasileiras. Irigaray e Vergara (2011) levantaram que é necessário haver a análise crítica da diversidade em pesquisas, mas se pode acrescentar que essa análise deve fazer parte da agenda das empresas. Refletir sobre a diversidade é ponto crucial para que as mudanças possam ocorrer de maneira gradativa e saudável.

\section{Referências}

ALVES, Mario Aquino. GALEÃO-SILVA, Luis Guilherme. A crítica da gestão da diversidade nas organizações. Rev. adm. empre, São Paulo, v. 44, n. 3, p. 20-29, Jul./Set. 2004.

CARVALHO, Antonio Vieira de. NASCIMENTO, Luiz Paulo do. SERAFIM, Oziléa Clen Gomes. Administração de recursos humanos. 2. ed. São Paulo: Cengage Learning, 2012.

CRESWELL, John W. Projeto de pesquisa: métodos qualitativo, quantitativo e misto; tradução Luciana de Oliveira da Rocha. 2. ed. Porto Alegre: Artmed, 2007. 248 p.

FLEURY, Maria Tereza Leme. Gerenciando a diversidade cultural: experiências de empresas brasileiras. Rev. adm. empre, São Paulo, v. 40, n. 3, p. 18-25, Jul./Set. 2000.

FONSECA, J. J. S. Metodologia da pesquisa científica. Fortaleza: UEC, 2002. Apostila. 127 p.

GERHARDT, Tatiana Engel; SILVEIRA, Denise Tolfo. Métodos de pesquisa. Porto Alegre: Editora da UFRGS, 2009. 120 p.

GIL, Antonio Carlos. Como elaborar projetos de pesquisa. 4. ed. São Paulo: Atlas, 2008. $175 \mathrm{p}$.

IRIGARAY, Hélio Arthur Reis; VERGARA, Sylvia Constant. O tempo como dimensão de pesquisa sobre uma política de diversidade e relações de trabalho. Cadernos EBAPE.BR, Rio de Janeiro, v. 9, n. 4, p. 1085 a 1098, jan. 2011. ISSN 1679-3951. Disponível em: <http://bibliotecadigital.fgv.br/ojs/index.php/cadernosebape/article/view/5235>. Acesso em: 13 mar. 2019. 
Kohn, Stephanie. Samsung aposta em diversidade e garante reconhecimento do público. Canaltech. 2019. Disponível em: <https://canaltech.com.br/marketing/samsung-aposta-emdiversidade-e-garante-reconhecimento-do-publico-130837/>. Acesso em: 15 de abr. 2019.

PLATAFORMA SUCUPIRA. Qualis. Disponível em: <https://sucupira.capes.gov.br/sucupira/public/index.jsf\#>. Acesso em: 06 mar. 2019.

PRODANOV, Cleber Cristiano; FREITAS, Ernani Cesar de. Metodologia do trabalho científico: métodos e técnicas da pesquisa e do trabalho acadêmico. 2. ed. Novo Hamburgo: Feevale, 2013.

ROBBINS, Stephen. Comportamento organizacional. 11. ed. São Paulo: Pearson Prentice Hall, 2005.

SARAIVA, Luiz Alex Silva; IRIGARAY, Hélio Arthur dos Reis. Políticas de diversidade nas organizações: uma questão de discurso?. Rev. adm. empre, São Paulo , v. 49, n. 3, p. 337-348, Set. 2009. Disponível em: $<$ http://www.scielo.br/scielo.php?script=sci_arttext\&pid=S003475902009000300008\&lng=en\&nrm=iso>. Acesso em: 13 mar. 2019.

SOTO, Eduardo. Comportamento Organizacional: o impacto das emoções. São Paulo: Cengage Learning, 2010. 